\title{
IMPACT OF MCCD WORKSHOP ON KNOWLEDGE AND AWARENESS IN POST GRADUATE RESIDENTS AT A TERTIARY CARE TEACHING HOSPITAL

\author{
Sandeep S. Kadu ${ }^{1}$, Atul A. Khalkar ${ }^{2}$ \\ ${ }^{1}$ Professor and Head, Department of Forensic Medicine and Toxicology, \\ ${ }^{2}$ Professor, Department of General Surgery, DVVPF's Medical College, Ahmednagar, Maharashtra, India.
}

\begin{abstract}
Background: Medical Certificate of Cause of Death is a vital document, important scientific tool issued by the doctors. It is the physician's primary responsibility to complete the medical certificate of cause of death correctly. Incorrect filling up of the certificate will result in gross errors in legal scrutiny in medico-legal deaths. Method: At the beginning the self-designed, pretested questionnaire open ended was distributed to participants, immediately after distribution pre-test was conducted. After the pre-test an interactive workshop was conducted on the MCCD. After the workshop post test was conducted. Result: There was an increase in the knowledge about who issues death certificates, long form of MCCD, who issues death certificate, maximum period within which you have to inform the registrar office about death in your clinic/hospital, detent dead body until your bills paid, what matter you are going to write on 1a. column and version present available in medical students from $0 \%$ to $61 \%, 30 \%$ to $100 \%, 0 \%$ to $91 \%$, $0 \%$ to $91 \%, 70 \%$ to $96 \%, 26 \%$ to $87 \%$ and $39 \%$ to $100 \%$ respectively. Conclusion: In the present study there is an improvement in knowledge and awareness in post graduates students after an interactive workshop on the MCCD.
\end{abstract}

Keywords: Medical Certificate of Cause of Death; Educational intervention; Postgraduate students.

\section{INTRODUCTION}

Issuing Medical Certificate of Cause of Death (MCCD) is done immediately after deciding the person is dead, by the same medical officer who has declared the person dead. Correct knowledge of the cause of death is essential as future course [1]. It is a vital document, important scientific tool issued by the doctors [2]. It is the physician's primary responsibility to complete the medical certificate of cause of death correctly [3]. Incorrect filling up of the certificate will result in gross errors in legal scrutiny in medico-legal deaths [4]. Accuracy in certifying the cause of death is desirable at many levels as it affects health statistics. There are many rules and regulations about filling and issuing this certificate. World Health Organization endorsed the system of International Classification of Diseases (ICD) in 1990 report on MCCD. The causes of deaths has been tabulated as per the National List (ICD -10, modified according to Indian conditions [5]. Study was designed to educate and make them aware of importance of correct medical certification of death by using workshop as intervention. Increased education and better documentation leads to reduction in errors and improves the legitimacy of death certificates.

Purpose of study: The study was designed to see if any improvement could be brought about Medical Certification of Cause of Death

Aim: To analyse the impact of MCCD workshop

\begin{tabular}{l} 
DOI: $10.31878 /$ ijcbr.2018.51.05 \\
iSSN $2395-0471$ \\
\hline
\end{tabular}

(Educational intervention) on knowledge and awareness in $\mathrm{PG}$ residents

\section{MATERIALS AND METHODS}

Study design: An interventional study

Ethics approval: The study was approved by the Institutional Ethics committee and informed consent was taken from the participants before the study commencement

Study duration: 3 months

Study place: DVVPF's Medical College and Hospital, Ahmednagar, Maharashtra.

Sample size: 46 members of $P G$ residents

\section{Inclusion criteria:}

Exclusion criteria: Participants included during the pre -test (Before study) were excluded during actual study

Methodology: At the beginning the self-designed, pretested questionnaire open ended was distributed to participants, immediately after distribution pre-test was conducted (Annexure 1). After the pre-test an interactive workshop was conducted on the MCCD. After the workshop post test was conducted.

Statistical analysis: The data was represented in form of percentage and statistical analysis was done by using chi-square test

\section{Annexure 1: Questionnaire}

Who issues death certificates

What is the long from of MCCD?

Correspondence: Dr. Atul A.Khalkar, Professor, Department of General Surgery, DVVPF's Medical College, Ahmednagar, Maharashtra. E-mail: atulkhalkar24@gmail.com

(C) Authors; 2019. International Journal of Clinical and Biomedical Research, Sumathi Publications.

This is an Open Access article which permits unrestricted non-commercial use, provided the original work is properly cited. 
Who design the format of MCCD?

According the birth and death registration act 1969, what is the maximum period within which you have to inform the registrar office about death in your clinic/hospital?

Patient is not paying bills of your hospital, are you going to detent dead body until your bills paid?

What matter you are going to write on 1a. Column of MCCD?

Which version is currently available?

\section{RESULTS}

mat of MCCD in medical students from $0 \%$ to $91 \%$ ( $\mathrm{p}$ value $<0.001)$, There was an increase in the knowledge about maximum period to inform the registrar in medical students from $0 \%$ to $91 \%$. ( $p$ value $<$ 0.001 ), an increase in the knowledge about going to detent dead body until your bills paid in medical students from $70 \%$ to $96 \%$. ( $p$ value $<0.001$ ), an increase in the knowledge about what matter you are going to write on 1a. Column of MCCD in medical students from $26 \%$ to $87 \%$. ( $\mathrm{p}$ value $<0.001$ ) and there was an increase in the knowledge about which version is currently available in medical students from $39 \%$ to $100 \%$. ( p value $<0.001)$

In the present study it is revealed that a significant reduction in the error after the post workshop,

In the present study total 46 participants were included and the questionnaire was consists of 7 questions. After the completion of the pre and post-test the following observations were made:

\begin{tabular}{|c|c|c|c|c|c|c|}
\hline \multirow{2}{*}{$\begin{array}{l}\text { Question } \\
\text { number }\end{array}$} & \multicolumn{2}{|c|}{ Pre tested } & \multicolumn{2}{|c|}{ Post tested } & \multirow{2}{*}{$\begin{array}{l}\text { Chi square } \\
\text { value }\end{array}$} & \multirow{2}{*}{$P$ value } \\
\hline & Correct & Incorrect & Correct & Incorrect & & \\
\hline 1 & 0 & 46 & 28 & 18 & 40.25 & $0.000 * *$ \\
\hline 2 & 14 & 32 & 46 & 0 & 49.07 & $0.000 * *$ \\
\hline 3 & 0 & 46 & 42 & 4 & 77.28 & $0.000 * *$ \\
\hline 4 & 0 & 46 & 40 & 6 & 70.77 & $0.000 * *$ \\
\hline 5 & 32 & 14 & 44 & 2 & 10.89 & $0.000 * *$ \\
\hline 6 & 12 & 34 & 40 & 6 & 34.68 & $0.000 * *$ \\
\hline 7 & 18 & 28 & 46 & 0 & 40.25 & $0.000 * *$ \\
\hline
\end{tabular}

\section{DISCUSSION}

Amul B Patel noted major errors in 23(57.5\%) certificates, commonest being improper sequencing (55\%) [8]. Ahmed Suleman Haque observed 124 (62\%) certificates with inappropriate immediate and underlying cause of death [9].

In the present study we found that the doctors are finding it difficult to correctly fill the immediate cause of death. Only $14 \%$ could correctly fill this column. Astonishingly, $86 \%$ of the doctors are confused between the terms, cause of death and modes of death [6].

Shobha Misra observed that during the pre-test, although the participants mentioned gender and age, the name of the deceased was frequently missing and it was significantly improved post-test [7].

According the studies b Villa J [10], Lu TH [11] the most frequent error in pre workshop was in listing the mechanism of death followed by the proper underlying the cause of death and it was dropped to one third following the workshop.

In the present study the there was an increase in the knowledge about who issues death certificates in medical students from $0 \%$ to $61 \%$. ( $p$ value $<0.001$ ), an increase in the knowledge about long form of MCCD in medical students from $30 \%$ to $100 \%$ (p value $<0.001$ ), an increase in the knowledge about who design the for-

\section{CONCLUSION}

In the present study there is an improvement in knowledge and awareness in post graduates students after an interactive workshop on the MCCD. There is a need to adopt multi-faceted approach to increase knowledge and awareness about rules, regulations of MCCD in doctors to improve accuracy and reliability of data

Conflict of interest: Nonce declared by authors

Source of funding: Nil

\section{REFERENCES}

1. Kotabagi RB, Chaturvedi RK, Banerjee A. Medical Certification of Cause of Death. MJAFI 2004; 60 : 261-272

2. Aarati Pokale, Mandar D Karmarkar. Knowledge of Medical Certificate of Cause of Death amongst Doctors and Errors in Certification. Indian Journal of Forensic and Community Medicine, JulySeptember 2016;3(3):156-162

3. Completing medical certificates of death: Who's responsible? Available online at: https:// www.cmpa-acpm.ca/en/advice-publications/ browse-articles/2016/completing-medicalcertificates-of-death-who-s-responsible. published 
March 2016 / Revised June 2016

4. Arthur E. Westveer. Managing death investigations. Property of National Criminal Justice Reference Service $\{$ NOJRS $\}$. Revised, 1997. Available online at https://www.ncjrs.gov/ pdffiles1/ Digitization/196709NCJRS.pdf

5. Report on medical certification of cause of death 2014. Office of the Registrar General, India Government of India, ministry of home affairs, vital statistics division, RK puram, New Delhi. Available at http://www.censusindia.gov.in/2011Documents/mccd_Report1/ mccd_report_2014.pdf

6. Swapnil S Agarwal, Vijay Kumar A G, Lavlesh Kumar, Binay K Bastia, Krishnadutt H Chavali. Study on Appraisal of Effectiveness of the MCCD Scheme

7. Shobha Misra, Chintan Dashratha, Baxi RK, Vihang Mazumdar, Parag Chavda. Evaluation of Medical Certificate of Cause of Death (MCCD) Training imparted to Medical Officers of Vadodara District located in Gujarat. Healthline 2014;5(2):60 $-63$

8. Amul B. Patel, Hitesh Rathod, Himanshu Rana, Viren Patel. Assessment of Medical Certificate of Cause of Death at a New Teaching Hospital in Vadodara. NJCM 2011;2:349-353.

9. Ahmed Suleman Haque, Kanza Shamim, Najm Hasan Siddiqui, Muhammad Irfan, Javaid Ahmed Khan. Death Certificate Completion Skills of Hospital Physicians in a Developing Country. BMC Health Services Research 2013, 13:205. Available at: http://www.biomedcentral.com/1472$6963 / 13 / 205$.

10. Villar J, Perez Mendez L. Evaluating an educational intervention improve the accuracy of death certification among trainees from various specialities. BMC health Serv Res. 2007;7:183

11. Lu Th, Shih TP, Lee MC. Diversity in death certification. A case vignette approach. J Clin Epidemol. 2001;54(11):1086-93 